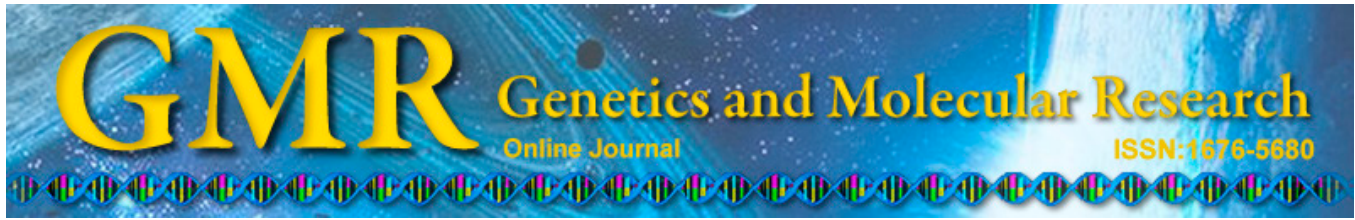

\title{
Protective effect of proanthocyanidin against oxidative ovarian damage induced by 3-nitropropionic acid in mice
}

\author{
J.Q. Zhang ${ }^{1,2}$, B.S. Xing ${ }^{2}$, C.C. Zhu ${ }^{1}$, M. Shen ${ }^{1}$, F.X. Yu ${ }^{1}$ and H.L. Liu ${ }^{1}$ \\ ${ }^{1}$ College of Animal Science and Technology, Nanjing Agricultural University, \\ Nanjing, Jiangsu, China \\ ${ }^{2}$ Institute of Animal Husbandry and Veterinary Science, Henan Academy of \\ Agricultural Sciences, Zhengzhou, China \\ Corresponding author: H.L. Liu \\ Email: liuhonglin@njau.edu.cn
}

Genet. Mol. Res. 14 (1): 2484-2494 (2015)

Received July 30, 2013

Accepted January 15, 2015

Published March 30, 2015

DOI http://dx.doi.org/10.4238/2015.March.30.6

\begin{abstract}
Oxidative stress, which poses a threat to reproductive health, causes many serious female reproductive diseases. In this study, we investigated whether proanthocyanidins (PC) have a protective effect against oxidative stress-induced ovarian damage. Forty female ICR mice were randomized into 4 groups: a control group, a control plus PC group, a 3-nitropropionic acid (3-NPA) group, and a 3-NPA plus PC group. An ovarian oxidative stress model induced by $3-\mathrm{NPA}$ was constructed using female ICR mice. After the animals were sacrificed, their ovaries were collected to measure reactive oxygen species (ROS) levels, the activities of superoxide dismutase (SOD) and catalase (CAT), and the mRNA expression levels of relevant granulosa cell apoptosis genes (Bcl-2, Bax, Bim, FasL, and caspase-3). We also conducted a histological evaluation of granulosa cell apoptosis and follicular atresia. The results showed that compared to the 3-NPA group, ROS levels and activities of T-SOD and CAT in the 3-NPA plus $\mathrm{PC}$ group were significantly decreased $(\mathrm{P}<0.05)$, while the ratio of
\end{abstract}


Bcl-2 to Bax in the 3-NPA plus PC group were significantly increased $(\mathrm{P}<0.05)$. mRNA expression levels of Bim, FasL, and caspase-3 in the 3 -NPA plus PC group were significantly decreased $(\mathrm{P}<0.05)$, and the percentage of atretic follicles and granulosa cell apoptosis in the 3-NPA plus $\mathrm{PC}$ group was significantly decreased $(\mathrm{P}<0.05)$. Collectively, these data indicate that $\mathrm{PC}$ has significant protective effects against damage induced by oxidative stress in mouse ovaries. The mechanisms of protection may be related to antioxidation and apoptosis reduction.

Key words: 3-NPA; Proanthocyanidins; Oxidative stress; Ovary

\section{INTRODUCTION}

Reactive oxygen species (ROS), such as the superoxide anion $\left(\mathrm{O}_{2}^{-}\right)$, hydrogen peroxide $\left(\mathrm{H}_{2} \mathrm{O}_{2}\right)$, and the hydroxyl radical $(\cdot \mathrm{OH})$, are formed continuously in cells as a consequence of the mitochondrial respiratory chain and external factors such as exposure to toxic chemical waste, direct and second-hand cigarette smoke, gasoline exhaust, urban air pollutants, ozone radiation, and physical stress. At physiologically low levels, ROS play an important regulatory role in various signaling transduction pathways during folliculogenesis, oocyte maturation, and embryogenesis (Agarwal et al., 2008). However, excessive ROS generation can damage cellular components, including lipids, proteins, and nucleic acids (Circu and Aw, 2010). Therefore, ROS overproduction and accumulation in the ovary have detrimental effects on follicular function and contribute significantly to female reproductive diseases (Agarwal et al., 2005). The female ovary produces oocytes and regulating hormones. Excess ROS generation within the follicle causes oxidative stress and induces granulosa cell apoptosis and follicular atresia, as well as damage to oocytes (Jančar et al., 2007; Tamura et al., 2008). Several studies have indicated the importance of oxidative stress in triggering granulosa cell apoptosis, which is a major cause of follicular atresia (Tilly and Tilly, 1995; Murdoch, 1998). Most atresia in the adult ovary occurs in the antral follicles (Hirshfield, 1988; Tilly and Robles, 1999), where atresia is driven by apoptosis of the granulosa cells, leading to oocyte death (Tilly and Robles, 1999).

Release of $\mathrm{O}_{2}^{-}$from the mitochondria is the main source of cellular oxidative stress. Several oxidants, including $\mathrm{H}_{2} \mathrm{O}_{2}$, nicotine, lead $(\mathrm{Pb})$, methoxychlor, and 3-nitropropionic acid (3-NPA), cause oxidative stress and induce cell apoptosis (Taupeau et al., 2001; Yoon et al., 2002; Şener et al., 2005; Gupta et al., 2006). Among these, 3-NPA is the most effective for producing high ROS levels and triggering follicular granulosa apoptosis (Shen et al., 2012). 3-NPA, a natural toxin produced by various plants and fungi, is an inhibitor of succinate dehydrogenase and induces oxidative stress of mitochondrial origin (Fontaine et al., 2000; Kim et al., 2000). ROS levels that were specifically increased in follicular granulosa cells, but not other tissues, were detected following intraperitoneal injection of mice with 3-NPA (Shen et al., 2012). 3-NPA can significantly increase the production of lipid peroxides and oxidized protein levels both in the mitochondria and in the cytosol (Fu et al., 1995). These data suggest that 3-NPA can generate highly reactive free radicals and induce oxidative stress, which may be useful as an in vivo ovarian oxidative stress model.

Oxidative stress-induced damage can be prevented by several antioxidants, including superoxide dismutase (SOD), catalase (CAT), ascorbic acid (vitamin C), vitamin E, and Nacetyl-L-cysteine (Chandra et al., 2000; Hogg, 2008). Proanthocyanidins (PCs) are powerful, 
naturally occurring polyphenolic antioxidants that are widely present in fruits, vegetables, seeds, nuts, flowers, and bark (Rice-Evans and Packer, 2010). PCs have were reported to possess a broad spectrum of pharmacological and medicinal properties against oxidative stress (Bagchi et al., 2002). They also have strong antioxidant activities, and their $\mathrm{O}_{2}^{-}$radical-scavenging activities are 10-30 times higher than those of the antioxidant vitamins $\mathrm{C}$ and $\mathrm{E}$ ( $\mathrm{Lu}$ and Yeap Foo, 2000). Many studies on PCs have shown that they can provide significant protection against $\mathrm{H}_{2} \mathrm{O}_{2}$-induced oxidative damage to PC-12 cells (Bagchi et al., 1998b), tobaccoinduced apoptotic cell death (Bagchi et al., 1999a), and oxidative stress-induced gastrointestinal injury (Bagchi et al., 1999b), as well as protect multiple organs from a variety of toxic assaults (Ray et al., 1999), but the effects of PCs on ovarian oxidative damage have not been thoroughly studied.

In this study, we examined whether PC, as a potent free radical scavenger, could ameliorate ovarian oxidative injury through its antioxidant properties.

\section{MATERIAL AND METHODS}

\section{Animals}

Female ICR mice ( $20 \pm 2 \mathrm{~g}$ and 4 weeks old) were obtained from the Experimental Animal Center of Qing Long Shan, Nanjing, China. The mice were housed in plastic cages in a room kept under standardized conditions at a temperature of $22^{\circ}-24^{\circ} \mathrm{C}, 20 \%$ humidity, and a 12-h light/dark cycle, with free access to tap water and food throughout the study. Mice were allowed to acclimatize for 1 week before beginning the experiments. Animal experiments were conducted under the principles of good laboratory animal care and were approved by the ethics committee for laboratory animal care and use of Nanjing Agricultural University, China.

\section{Drugs and reagents}

PC was obtained from Zelang Medical Technology Company (Nanjing, China; purity $\geq 95 \%$ ). Kits for testing SOD and CAT activities were purchased from Nanjing Jiancheng Bioengineering Institute (Jiangsu, China). 3-NPA was acquired from Sigma-Aldrich (St. Louis, MO, USA). An intracellular ROS red fluorescence determination kit and tissue and cellular $\mathrm{O}_{2}^{-}$colorimetric quantitative determination kits were purchased from GENMED (Shanghai, China). The in situ cell death fluorescein detection kit (Lot No. 12486400) was obtained from Roche (Mannheim, Germany). All other chemicals used were of analytical grade.

\section{Experimental design and treatment}

All mice were randomly divided into 4 groups of 10 mice in each: a control group, in which animals were given normal saline orally twice daily for 14 days, a control plus PC group, in which animals were given a PC solution orally twice daily for 14 days, a 3-NPA group, a model group in which animals were given normal saline orally twice daily for 14 days and beginning on the 7th day, animals were treated with 3-NPA for 7 days, and a 3-NPA plus PC group, in which animals were given a PC solution orally twice daily for 14 days and on the 7th day, animals were injected with 3-NPA for 7 days. The total duration of the experiment was 14 days. 3-NPA was dissolved in normal saline and the $\mathrm{pH}$ was adjusted to 7.4 with 
sodium hydroxide. Animals were injected intraperitoneally with $12.5 \mathrm{mg} / \mathrm{kg} 3-\mathrm{NPA}$ twice daily for 7 consecutive days at 12-h intervals ( 8 a.m. and 8 p.m.). The dose of 3-NPA used in the study was based on doses used in literature published from our laboratory (Shen et al., 2012). PC was dissolved in normal saline and supplemented to the animals by intragastric administration twice daily at a dose of $100 \mathrm{mg} / \mathrm{kg}$ body weight because this was reported to be the most effective dose (Bagchi et al., 1998a; Sato et al., 1999). Vaginal smears were performed to determine the estrous stage at the time of tissue collection (Champlin et al., 1973). After estrous cyclicity, data were collected, the animals were sacrificed by cervical dislocation, and all ovaries were removed and collected. Granulosa cells were obtained from the left ovaries for measurement of ROS levels and subsequent RNA extraction. The right ovaries were fixed in 4\% paraformaldehyde with 0.01 $\mathrm{M}$ phosphate-buffered saline (PBS) at $4^{\circ} \mathrm{C}$ overnight and embedded in paraffin for the terminal deoxynucleotidyl transferase dUTP nick-end labeling (TUNEL) assay.

\section{Measurement of intracellular ROS}

On day 15 , ICR mice from different treatment groups $(\mathrm{N}=5$ /group) were sacrificed by cervical dislocation and the left ovaries were collected for measurement of granulosa cell ROS levels. Follicular granulosa cells were collected by puncture of the dominant ovarian follicle $(>200 \mu \mathrm{m})$ in the left ovary. ROS levels in granulosa cells were measured using the intracellular ROS red fluorescence determination kit and cellular $\mathrm{O}_{2}^{-}$colorimetric quantitative determination kit. ROS levels in ovarian tissue were measured using the tissue $\mathrm{O}_{2}^{-}$colorimetric quantitative determination kit. All procedures were performed according to manufacturer instructions.

\section{in situ TUNEL analysis of apoptosis}

The right ovaries were fixed in $4 \%$ paraformaldehyde for the TUNEL assay. The procedure was performed according to the in situ cell death detection kit protocol. Briefly, ovaries embedded in paraffin were cut every $6 \mu \mathrm{m}$ and sections were placed onto glass slides. After deparaffinization and rehydration, ovarian sections were incubated with $200 \mu \mathrm{g} / \mathrm{mL}$ proteinase-K for $15 \mathrm{~min}$ at $37^{\circ} \mathrm{C}$ and rinsed with PBS for $20 \mathrm{~min}$. Ovaries were then incubated in a humidified chamber with $0.1 \%$ Triton $100 \mathrm{X}$ for $10 \mathrm{~min}$ at $4^{\circ} \mathrm{C}$, washed for $20 \mathrm{~min}$ with PBS, and terminal deoxynucleotidyl transferase (TdT) stained for $1 \mathrm{~h}$ at $37^{\circ} \mathrm{C}$, after which the sections were stained with 4'6-diamidino-2-phenylindole (DAPI). Images were obtained using a laser scanning confocal microscope (Zeiss, Oberkochen, Germany). Follicles were classified as atretic if surrounded by 5 or more TUNEL-positive granulosa cells (Hamm et al., 2004). Atretic follicles were counted in sections acquired at the maximum diameter of each ovary.

\section{Determination of total ovarian SOD and CAT}

One gram each ovarian tissue ( $\mathrm{N}=5$ /group) were collected and homogenized in $9 \mathrm{~mL}$ cold normal saline and the homogenate was stored at $-20^{\circ} \mathrm{C}$ before analysis. The Coomassie Blue protein binding method was used to determine protein concentrations using bovine serum albumin (BSA) as a standard. SOD and CAT activities were measured using commercial kits (Nanjing Jiancheng Bioengineering Institute, Nanjing, China). The determination of SOD activity was based on the production of anions by the xanthine/xanthine oxidase system. T-SOD activity was expressed as U/mg protein. CAT activity was measured spectrophoto- 
metrically as the decomposition of $\mathrm{H}_{2} \mathrm{O}_{2}$ at $240 \mathrm{~nm}$. An enzyme activity unit was defined as the degradation of $\mathrm{H}_{2} \mathrm{O}_{2}$ (the absorbance of the substrate was 0.50-0.55) per second per gram tissue protein; enzymatic activity was expressed as $\mathrm{U} / \mathrm{g}$ protein.

\section{Real-time quantitative polymerase chain reaction (PCR) analysis}

Total RNA was extracted from granulosa cells using TRIzol reagent (Invitrogen, Carlsbad, CA, USA) according to the manufacturer protocol. Optical densities at $260 \mathrm{~nm}$ and $280 \mathrm{~nm}$ were measured to determine the quantity and purity of RNA samples. Next, $2 \mathrm{mg}$ total RNA was subjected to reverse transcription with a RevertAid ${ }^{\mathrm{TM}} \mathrm{RT}$ reagent kit (Fermentas; Thermo Fisher Scientific; Pittsburgh, PA, USA) in a $25 \mu \mathrm{L}$ reaction mixture according to the manufacturer protocol. Quantitative reverse transcription (RT)-PCR was performed with SYBR Premix Ex Taq (Takara, Otsu, Japan) in a $20 \mu \mathrm{L}$ reaction volume. Primers for apoptosisrelated genes (Bcl-2, Bax, Bim, FasL, and caspase-3) were designed using the Primer 5 software (Table 1). Glyceraldehyde 3-phosphate dehydrogenase (GAPDH) was used as an internal control. Each sample was run in triplicate.

\begin{tabular}{|c|c|c|c|c|}
\hline Gene & Accession No. & Primer sequences $\left(5^{\prime}-3^{\prime}\right)$ & Product size (bp) & Annealing temperature $\left({ }^{\circ} \mathrm{C}\right)$ \\
\hline \multirow[t]{2}{*}{ GAPDH } & NM_008084.2 & F: ATGGTGAAGGTCGGTGTGAACG & & \\
\hline & & R: CTCGCTCCTGGAAGATGGTGATG & 452 & 56 \\
\hline \multirow[t]{2}{*}{ Bax } & NM_007527.3 & F: CCAGGATGCGTCCACCAAGA & & \\
\hline & & R: GGTGAGGACTCCAGCCACAA & 394 & 57 \\
\hline \multirow[t]{2}{*}{ Bcl-2 } & NM 009741.3 & F: GTGGATGACTGAGTACCTGAACC & & \\
\hline & & R: AGCCAGGAGAAATCAAACAGAG & 120 & 60 \\
\hline \multirow[t]{2}{*}{ Bim } & NM 009754.3 & F: TATGGAGAAGGCATTGAC & & \\
\hline & & R: TGTGGTGATGAACAGAGG & 207 & 56 \\
\hline \multirow[t]{2}{*}{ FasL } & NM_010177.4 & F: GGGTCTACTTACTACCTCAC & & \\
\hline & & R: CCCTCTTACTTCTCCGTTA & 192 & 57 \\
\hline \multirow[t]{2}{*}{ Caspase-3 } & NM_009810.2 & F: ACAGCACCTGGTTACTATTC & & \\
\hline & & R: CAGTTCTTTCGTGAGCAT & 255 & 54 \\
\hline
\end{tabular}

\section{Statistical analysis}

Data are reported as means \pm standard error (SE). Statistical differences were analyzed by one-way analysis of variance using the SPSS version 16.0 software (SPSS Inc., Chicago, IL, USA). P values of less than 0.05 were considered to be statistically significant.

\section{RESULTS}

\section{Effect of PC on ROS levels in granulosa cells and ovarian tissue}

Mice treated with 3-NPA alone showed a significant increase in ROS levels in follicular granulosa cells and ovarian tissue compared to controls $(\mathrm{P}<0.05)$ (Figure 1A-C). ROS levels in follicular granulosa cells were detected by dihydroethidium bromide fluorescence, Fluorescence levels were significantly elevated in the 3-NPA-treated animals compared to controls (Figure 1A). ROS levels in follicular granulosa cells and ovarian tissue were quantified by Nitro blue tetrazolium (NBT) staining (Figure 1B and C). This change was prevented 
by prior and concurrent supplementation of PC in 3-NPA plus PC-treated animals when compared to animals treated with 3-NPA alone.
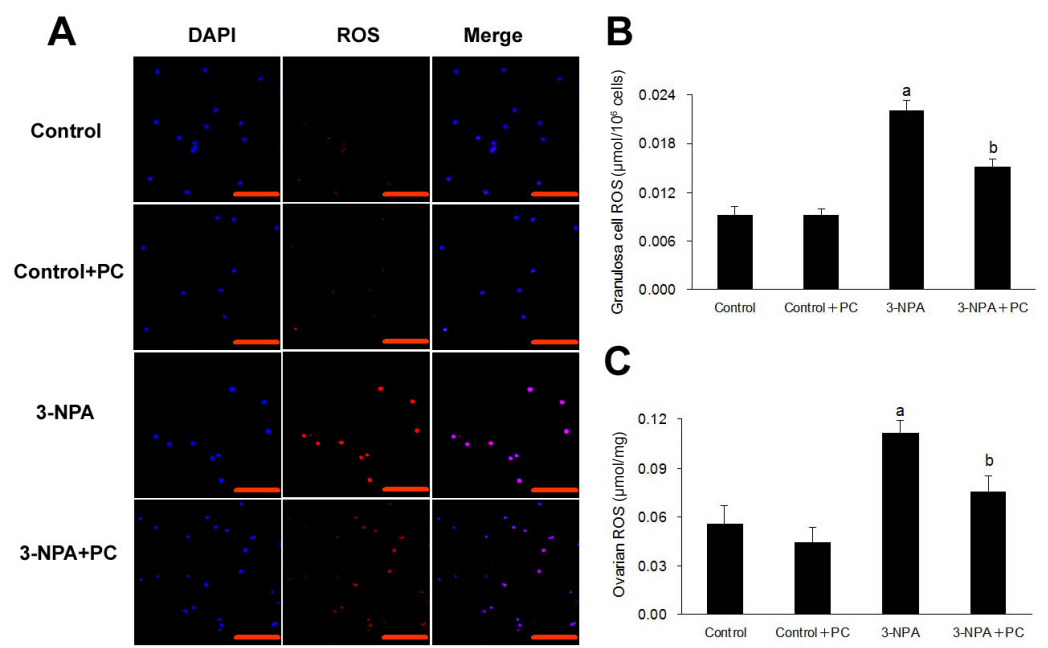

Figure 1. Effects of proanthocyanidin (PC) on intracellular and ovarian reactive oxygen species (ROS) levels. Mice were treated with 3-nitropropionic acid (3-NPA) alone or in combination with PC. A. ROS levels in follicular granulosa cells. ROS levels were detected by dihydroethidium bromide fluorescence (red) and nuclei were counterstained with DAPI (blue). Scale bars are $100 \mu \mathrm{m}$. B. Quantification of intracellular ROS levels. C. Quantification of ovarian tissue ROS levels. ROS levels in follicular granulosa cells and ovarian tissue were quantified by Nitro blue tetrazolium (NBT) staining. Values are reported as means $\pm \mathrm{SE}$ (error bars; $\mathrm{N}=5$ ). ${ }^{\mathrm{a}} \mathrm{P}<0.05$ versus control group; ${ }^{b} \mathrm{P}<0.05$ versus $3-\mathrm{NPA}$-treated group.

\section{Effect of PC on ovarian SOD and CAT activity}

SOD is an antioxidant enzyme that dismutates the superoxide radical to $\mathrm{H}_{2} \mathrm{O}_{2}$. CAT is another endogenous antioxidant enzyme involved in the catalytic conversion of $\mathrm{H}_{2} \mathrm{O}_{2}$ to oxygen and water, decreasing oxidative stress. The data showed a significant increase in the activities of SOD and CAT with 3-NPA alone compared to controls $(\mathrm{P}<0.05)$ (Figure 2A and 2B). However, PC supplementation significantly decreased SOD and CAT activities in 3-NPA plus PC-treated animals compared to animals treated with 3-NPA alone.

\section{Effect of PC on granulosa cell apoptosis in ovarian follicles}

To examine the protective effect of PC supplementation on granulosa cell apoptosis in follicles, TUNEL staining was performed on paraffin sections of mouse ovaries to determine whether the number of apoptotic cells decreased in ovarian follicles of 3-NPA plus PC-treated animals. The results suggested that follicular granulosa cells exhibit significantly higher apoptosis rates in mice treated with 3-NPA alone compared to controls (Figure 3A). Furthermore, the percentage of atretic follicles was also significantly higher in 3-NPA-treated animals compared to controls. Compared with 3-NPA alone-treated animals, the percentage of granulosa cell apoptosis and atretic follicles was significantly lower in 3-NPA plus PC-treated animals (Figure $3 \mathrm{~A}$ and $3 \mathrm{~B}$ ). 


\section{A}

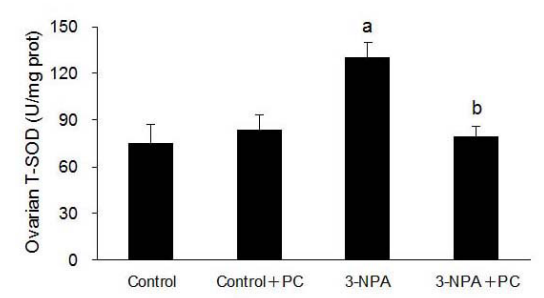

\section{B}

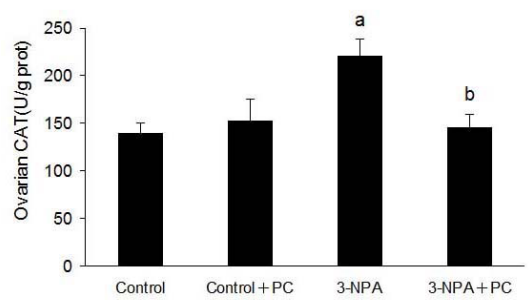

Figure 2. Effects of proanthocyanidin (PC) on antioxidant enzyme activity in ovarian tissue. Mice were treated with 3-nitropropionic acid (3-NPA) alone or in combination with PC. A. Activity of T-SOD in ovarian tissue. B. Activity of CAT in ovarian tissue. Values are reported as means $\pm \mathrm{SE}$ (error bars; $\mathrm{N}=5$ ). ${ }^{\mathrm{P}} \mathrm{P}<0.05$ versus control group; ${ }^{\text {b }}<0.05$ versus $3-N P A-t r e a t e d$ group.

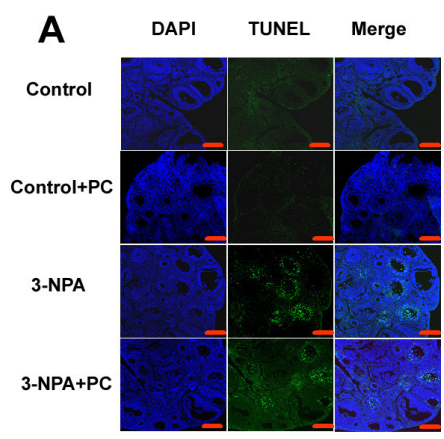

B

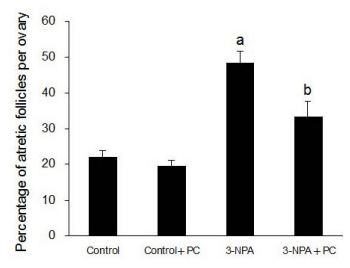

Figure 3. Effects of proanthocyanidin (PC) on oxidative stress-induced apoptosis in the ovary. Mice were treated with 3-nitropropionic acid (3-NPA) alone or in combination with PC. A. TUNEL assay of follicular granulosa cells in the ovarian sections. Apoptosis was detected by TUNEL staining (FITC labeling). Scale bars are $100 \mu \mathrm{m}$. B. Quantification of TUNEL-positive follicles. TUNEL-positive follicles were counted in sections taken at the maximum diameter of each ovary $(\mathrm{N}=5)$. Values are reported as means $\pm \mathrm{SE}$. ${ }^{\mathrm{a}} \mathrm{P}<0.05$ versus control group; ${ }^{\mathrm{b}}<$ 0.05 versus 3-NPA-treated group. 


\section{Effect of PC on expression of apoptosis-related genes in granulosa cells}

Quantitative RT-PCR was performed to examine the transcript levels of several apoptotic genes, including Bcl-2, Bax, Bim, FasL, and caspase-3 (Figure 4). The ratio of the relative levels of mRNA encoding Bcl-2 to Bax was lower $(\mathrm{P}<0.05)$ in 3-NPA alone-treated animals compared to controls. Compared with the 3-NPA alone-treated animals, the ratio of relative levels of mRNA encoding Bcl-2 to Bax was higher $(\mathrm{P}<0.05)$ in 3-NPA plus PC-treated animals. Bim, FasL, and caspase-3 mRNA expression levels were remarkably enhanced in the 3-NPA alone-treated animals compared to controls. Compared with 3-NPA alone-treated animals, Bim, FasL, and caspase-3 mRNA expression levels were significantly decreased in 3-NPA plus PC-treated animals.
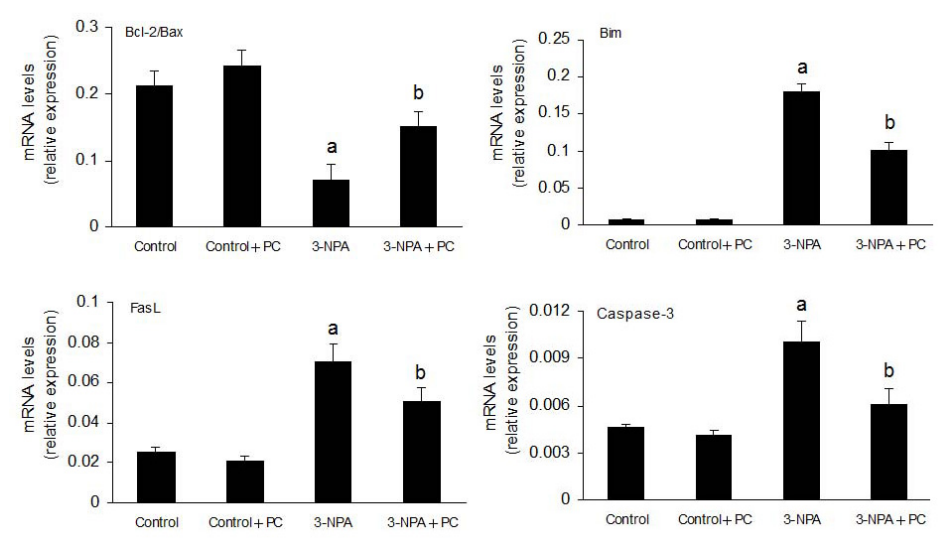

Figure 4. Effects of proanthocyanidin (PC) on mRNA levels of apoptosis-related genes in granulosa cells. Mice were treated with 3-nitropropionic acid (3-NPA) alone or in combination with PC. Quantitative RT-PCR was conducted to measure the corresponding mRNA levels. Relative expression data were normalized to the amount of cellular GAPDH. Values are reported as means \pm SE (error bars; $\mathrm{N}=5$ ). ${ }^{a} \mathrm{P}<0.05$ versus control group; ${ }^{\text {b }}<0.05$ versus 3-NPA-treated group.

\section{DISCUSSION}

Humans are continuously exposed to oxidative stress from metabolic processes (e.g., respiration, digestion, excretion) and environmental pollutants (e.g., cigarette smoking, pesticides, gasoline exhaust). Excessive oxidative stress is involved in the initiation and progression of granulosa apoptosis and follicular atresia in ovaries.

Although many oxidants exist, such as $\mathrm{H}_{2} \mathrm{O}_{2}, \mathrm{~Pb}$, and methoxychlor, as well as those acquired through smoking and consumption of alcohol, few of these factors have been thoroughly examined in ovarian oxidative stress studies. For example, long-term $\mathrm{Pb}$ treatment causes global oxidative damage (Taupeau et al., 2001) and long-term smoking results in serious lung diseases and cancer (Stämpfli and Anderson, 2009). Although methoxychlor can lead to follicular atresia in the mouse ovary, it also damages the liver, kidney, and cardiac cells through its toxic effects (Buczyńska and Szadkowska-Stańczyk, 2005). The oxidant 3-NPA reportedly generated oxidative stress in ovaries in a mouse model, in which ROS was specifically increased in follicular granulosa cells but not in other tissues (Shen et al., 2012). How- 
ever, little information exists regarding the effects of PC on ovarian oxidative stress in rodents. In this study, we used 3-NPA to induce ovarian oxidative stress to evaluate the effect of PC on granulosa cell apoptosis and follicular atresia.

Oxidative stress-induced apoptosis is thought to be a major cause of follicular atresia (Tilly and Tilly, 1995; Murdoch, 1998). Oxidative stress was reported to induce apoptosis by activating apoptosis-related gene expression converging on caspase- 3 , the executor of apoptosis. In this study, our data suggested that the mRNA expression levels of Bim, FasL, and caspase- 3 were upregulated, and the ratio between Bcl-2 and Bax was downregulated in mouse granulosa cells treated with 3-NPA alone compared with the control group. The elevated caspase- 3 mRNA expression suggests that caspase- 3 acts in concert with Bcl-2, Bax, Bim, and FasL in oxidative stress-induced granulosa cell apoptosis. Our data suggest that 3-NPA administration increased oxidative stress as shown by the increase in ROS production and induced granulosa cell apoptosis in follicles of 3-NPA-treated animals.

The free radical scavenging abilities of $\mathrm{PC}$ against biochemically generated $\mathrm{O}_{2}^{-}$and hydroxyl radicals were previously reported in vitro and in vivo in many studies. For example, pretreatment with PC could significantly decrease $\mathrm{H}_{2} \mathrm{O}_{2}$-induced oxidative damage in J774A.1 cells and PC-12 cells (Bagchi et al., 2000). Another study showed that $\mathrm{H}_{2} \mathrm{O}_{2}$-induced chromosomal damage could be prevented by PC treatment (Sugisawa et al., 2004), and pretreatment of $300 \mu \mathrm{g} / \mathrm{mL}$ tobacco-treated cells with $100 \mathrm{mg} \mathrm{PC} / \mathrm{L}$ significantly reduced tobacco-induced apoptosis in oral cells (Bagchi et al., 1999a). Furthermore, PC decreased lipid peroxidation and DNA fragmentation in the gastric and intestinal mucosa during acute stress (Bagchi et al., 2000). In our study, the decreased ROS levels in the 3-NPA plus PC-treated mice indicate that $\mathrm{PC}$ prevents ovarian damage by decreasing ROS production.

SOD and CAT are important enzymes in the defense system against oxidative stress. SOD can rapidly convert O2- to the less dangerous $\mathrm{H}_{2} \mathrm{O}_{2}$, which is further degraded by CAT to water. Many studies have shown that 3-NPA causes a corresponding increase in the activities of SOD and CAT (Fu et al., 1995; Binienda and Ali, 2001; Túnez et al., 2004). Increased enzyme activity is indicative of oxidative stress and reduces concentrations of ROS, preventing cell damage (Binienda et al., 1998; Binienda and Ali, 2001). Our study revealed that SOD and CAT levels were increased in the 3-NPA-treated animals, while PC supplementation significantly decreased the SOD and CAT levels in the PC plus 3-NPA-treated animals. The increases in enzyme activity in response to 3-NPA-induced ovarian oxidative stress may be an early attempt to protect the ovary from oxidative damage. Our results suggest that PC plays a protective role in restoring the antioxidant status to ameliorate mitochondrial oxidative stress.

Our findings indicate that oxidative stress plays an important role in ovarian damage. Our data suggest that PC has a potent ability to ameliorate oxidative stress-induced ovarian damage by enhancing the antioxidant capacity, thereby attenuating free radical induced damage, and can therefore be employed in protection against oxidative ovarian stress.

\section{ACKNOWLEDGMENTS}

Research supported by a grant from a key project of the Chinese National Program for Fundamental Research and Development (“973” Program 2007 \#CB947403 and 2014 \#CB138502). 


\section{REFERENCES}

Agarwal A, Gupta S and Sharma RK (2005). Role of oxidative stress in female reproduction. Reprod. Biol. Endocrinol. 3: 28. Agarwal A, Gupta S, Sekhon L and Shah R (2008). Redox considerations in female reproductive function and assisted reproduction: from molecular mechanisms to health implications. Antioxid. Redox. Signal.10: 1375-1403.

Bagchi D, Garg A, Krohn R, Bagchi M, et al. (1998a). Protective effects of grape seed proanthocyanidins and selected antioxidants against TPA-induced hepatic and brain lipid peroxidation and DNA fragmentation, and peritoneal macrophage activation in mice. Gen. Pharmacol. 30: 771-776.

Bagchi D, Kuszynski C, Balmoori J, Bagchi M, et al. (1998b). Hydrogen peroxide-induced modulation of intracellular oxidized states in cultured macrophage J774A.1 and neuroactive PC- 12 cells, and protection by novel grape seed proanthocyanidin extract. Phytother. Res. 12: 568-571.

Bagchi M, Balmoori J, Bagchi D, Ray SD, et al. (1999a). Smokeless tobacco, oxidative stress, apoptosis, and antioxidants in human oral keratinocytes. Free Radic. Biol. Med. 26: 992-1000.

Bagchi M, Milnes M, Williams C, Balmoori J, et al. (1999b). Acute and chronic stress-induced oxidative gastrointestinal injury in rats, and the protective ability of a novel grape seed proanthocyanidin extract. Nutr. Res. 19: 1189-1199.

Bagchi D, Bagchi M, Stohs SJ, Das DK, et al. (2000). Free radicals and grape seed proanthocyanidin extract: importance in human health and disease prevention. Toxicology 148: 187-197.

Bagchi D, Bagchi M, Stohs SJ, Ray SD, et al. (2002). Cellular protection with proanthocyanidins derived from grape seeds. Ann. N. Y. Acad. Sci. 957: 260-270.

Binienda ZK and Ali SF (2001). Neuroprotective role of L-carnitine in the 3-nitropropionic acid induced neurotoxicity. Toxicol. Lett. 125: 67-73.

Binienda Z, Simmons C, Hussain S, Slikker W Jr, et al. (1998). Effect of acute exposure to 3-nitropropionic acid on activities of endogenous antioxidants in the rat brain. Neurosci. Lett. 251: 173-176.

Buczyńska A and Szadkowska-Stańczyk I (2005). Identification of health hazards to rural population living near pesticide dump sites in Poland. Int. J. Occup. Med. Environ. Health. 18: 331-339.

Champlin AK, Dorr DL and Gates AH (1973). Determining the stage of the estrous cycle in the mouse by the appearance of the vagina. Biol. Reprod. 8: 491-494.

Chandra J, Samali A and Orrenius S (2000). Triggering and modulation of apoptosis by oxidative stress. Free Radic. Biol. Med. 29: 323-333.

Circu ML and Aw TY (2010). Reactive oxygen species, cellular redox systems, and apoptosis. Free Radic. Biol. Med. 48: 749-762.

Fontaine MA, Geddes JW, Banks A and Butterfield DA (2000). Effect of exogenous and endogenous antioxidants on 3-nitropionic acid-induced in vivo oxidative stress and striatal lesions: insights into Huntington's disease. $J$. Neurochem. 75: 1709-15.

Fu YT, He FS, Zhang SL and Zhang JS (1995). Lipid peroxidation in rats intoxicated with 3-nitropropionic acid. Toxicon. 33: 327-331.

Gupta RK, Miller KP, Babus JK and Flaws JA (2006). Methoxychlor inhibits growth and induces atresia of antral follicles through an oxidative stress pathway. Toxicol. Sci. 93: 382-389.

Hamm ML, Bhat GK, Thompson WE and Mann DR (2004). Folliculogenesis is impaired and granulosa cell apoptosis is increased in leptin-deficient mice. Biol. Reprod. 71: 66-72.

Hirshfield AN (1988). Size-frequency analysis of atresia in cycling rats. Biol. Reprod. 38: 1181-1188.

Hogg N (2008). Free radicals in disease seminars in reproductive endocrinology. Semin. Reprod. Endocrinol. 16: 241-248.

Jančar N, Kopitar AN, Ihan A, Klun IV, et al. (2007). Effect of apoptosis and reactive oxygen species production in human granulosa cells on oocyte fertilization and blastocyst development. J. Assist. Reprod. Genet. 24: 91-97.

Kim GW, Copin JC, Kawase M, Chen SF, et al. (2000). Excitotoxicity is required for induction of oxidative stress and apoptosis in mouse striatum by the mitochondrial toxin, 3-nitropropionic acid. J. Cereb. Blood Flow Metab. 20: 119-129.

Lu Y and Yeap Foo L (2000). Antioxidant and radical scavenging activities of polyphenols from apple pomace. Food Chem. 68: 81-85.

Murdoch W (1998). Inhibition by oestradiol of oxidative stress-induced apoptosis in pig ovarian tissues. J. Reprod. Fertil. 114: $127-130$.

Ray S, Hickey E and Bagchi D (1999). A novel grape seed proanthocyanidin extract (GSPE) protects multiple target organ toxicities induced by amiodarone (lung), dimethylnitrosamine (spleen), $\mathrm{CdCl} 2$ (kidney) and MOCAP (brain). FASEB J. 13: A187, Abstract 175.2.

Rice-Evans CA and Packer L (2010). Flavonoids in health and disease. CRC Press, Boca Raton. 
Sato M, Maulik G, Ray PS, Bagchi D, et al. (1999). Cardioprotective effects of grape seed proanthocyanidin against ischemic reperfusion injury. J. Mol. Cell Cardio. 31: 1289-1297.

Şener G, Özer Şehirli A, İpçi Y, Çetinel Ş, et al. (2005). Taurine treatment protects against chronic nicotine-induced oxidative changes. Fundam. Clin. Pharmacol. 19: 155-164.

Shen M, Lin F, Zhang J, Tang Y, et al. (2012). Invovlement of the upregulated FoxO1 expression in follicular granulosa cell apoptosis induced by oxidative stress. J. Biol. Chem. 287: 25727-25740.

Stämpfli MR and Anderson GP (2009). How cigarette smoke skews immune responses to promote infection, lung disease and cancer. Nat. Rev. Immunol. 9: 377-384.

Sugisawa A, Inoue $\mathrm{S}$ and Umegaki $\mathrm{K}$ (2004). Grape seed extract prevents $\mathrm{H}_{2} \mathrm{O}_{2}$-induced chromosomal damage in human lymphoblastoid cells. Biol. Pharm. Bull. 27: 1459-1461.

Tamura H, Takasaki A, Miwa I, Taniguchi K, et al. (2008). Oxidative stress impairs oocyte quality and melatonin protects oocytes from free radical damage and improves fertilization rate. J. Pineal. Res. 44: 280-287.

Taupeau C, Poupon J, Nomé F and Lefèvre B (2001). Lead accumulation in the mouse ovary after treatment-induced follicular atresia. Reprod. Toxicol. 15: 385-391.

Tilly J and Tilly K (1995). Inhibitors of oxidative stress mimic the ability of follicle-stimulating hormone to suppress apoptosis in cultured rat ovarian follicles. Endocrinology 136: 242-252.

Tilly J and Robles R (1999). Apoptosis and its impact in clinical reproductive medicine. Molecular biology in reproductive medicine. Parthenon, New York. pp. 79-101.

Túnez I, Montilla P, Del Carmen Muñoz M, Feijóo M, et al. (2004). Protective effect of melatonin on 3-nitropropionic acidinduced oxidative stress in synaptosomes in an animal model of Huntington's disease. J. Pineal. Res. 37: 252-256.

Yoon SO, Kim MM, Park SJ, Kim D, et al. (2002). Selenite suppresses hydrogen peroxide-induced cell apoptosis through inhibition of ASK1/JNK and activation of PI3-K/Akt pathways. FASEB J. 16: 111-113. 